OPEN ACCESS

Edited by:

Susan Carpenter,

University of California

San Francisco, USA

Reviewed by:

Philippe Georgel,

Strasbourg University, France

Frederick J. Sheedy,

Trinity College Dublin, Ireland

*Correspondence:

Paul J. Hertzog,

Centre for Innate Immunity and Infectious Diseases, Hudson Institute of Medical Research, 27-31 Wright

Street, Clayton, VIC 3168, Australia paul.hertzog@hudson.org.au

Specialty section:

This article was submitted to Molecular Innate Immunity, a section of the journal Frontiers in Immunology

Received: 01 May 2015 Accepted: 15 June 2015

Published: 08 July 2015

Citation: Forster SC, Tate MD and Hertzog PJ (2015) MicroRNA as type I

interferon-regulated transcripts and modulators of the innate immune response.

Front. Immunol. 6:334. doi: 10.3389/fimmu.2015.00334

\section{MicroRNA as type I interferon- regulated transcripts and modulators of the innate immune response}

\author{
Samuel C. Forster ${ }^{1,2,3}$, Michelle D. Tate ${ }^{1,2}$ and Paul J. Hertzog ${ }^{1,2 *}$ \\ ${ }^{1}$ Centre for Innate Immunity and Infectious Diseases, Hudson Institute of Medical Research, Clayton, VIC, Australia, \\ ${ }^{2}$ Department of Molecular and Translational Sciences, Monash University, Clayton, VIC, Australia, ${ }^{3}$ Host-Microbiota \\ Interactions Laboratory, Wellcome Trust Sanger Institute, Hinxton, UK
}

Type I interferons (IFNs) are an important family of cytokines that regulate innate and adaptive immune responses to pathogens, in cancer and inflammatory diseases. While the regulation and role of protein-coding genes involved in these responses are well characterized, the role of non-coding microRNAs in the IFN responses is less developed. We review the emerging picture of microRNA regulation of the IFN response at the transcriptional and post-transcriptional level. This response forms an important regulatory loop; several microRNAs target transcripts encoding components at many steps of the type I IFN response, both production and action, at the receptor, signaling, transcription factor, and regulated gene level. Not only do IFNs regulate positive signaling molecules but also negative regulators such as SOCS1. In total, 36 microRNA are reported as IFN regulated. Given this apparent multipronged targeting of the IFN response by microRNAs and their well-characterized capacity to "buffer" responses in other situations, the prospects of improved sequencing and microRNA targeting technologies will facilitate the elucidation of the broader regulatory networks of microRNA in this important biological context, and their therapeutic and diagnostic potential.

Keywords: microRNA, interferon, post-transcriptional regulation, systems biology, interferon-regulated genes

\section{Introduction}

The innate immune system provides the first line of defense against invading pathogens and plays a vital role in the detection of cellular disturbances. This system is initiated through activation of pattern recognition receptors (PRRs), such as the Toll-like receptors (TLRs) (1), Nod-like receptors (2), and RIG-I like helicases (3), which act as a sophisticated detection network, recognizing danger signals and initiating both intra- and intercellular responses. Importantly, the intercellular responses regulated through these pathways act to recruit and guide the broader immune response. The PRR intracellular signaling pathways are composed of well-characterized components including adaptors (e.g., MyD88, $\mathrm{TAB}$ ) and enzymes (e.g., IRAKs and IKKs) that activate two main transcription factors, namely NF- $\mathrm{KB}$, which drive pro-inflammatory cytokine gene transcription, and the IRFs, which drive expression of type I interferon (IFN) gene transcription (Figure 1). The type I IFNs are inducible cytokines that play an important role in many aspects of immunity (4) and have been shown to regulate over 2000 coding and non-coding large RNA transcripts, termed IFN-regulated genes (IRGs). This regulation occurs in a highly coordinated manner, the exact nature of which is dependent on subtype, timing, dosage, cell, and pathophysiological context (5). 


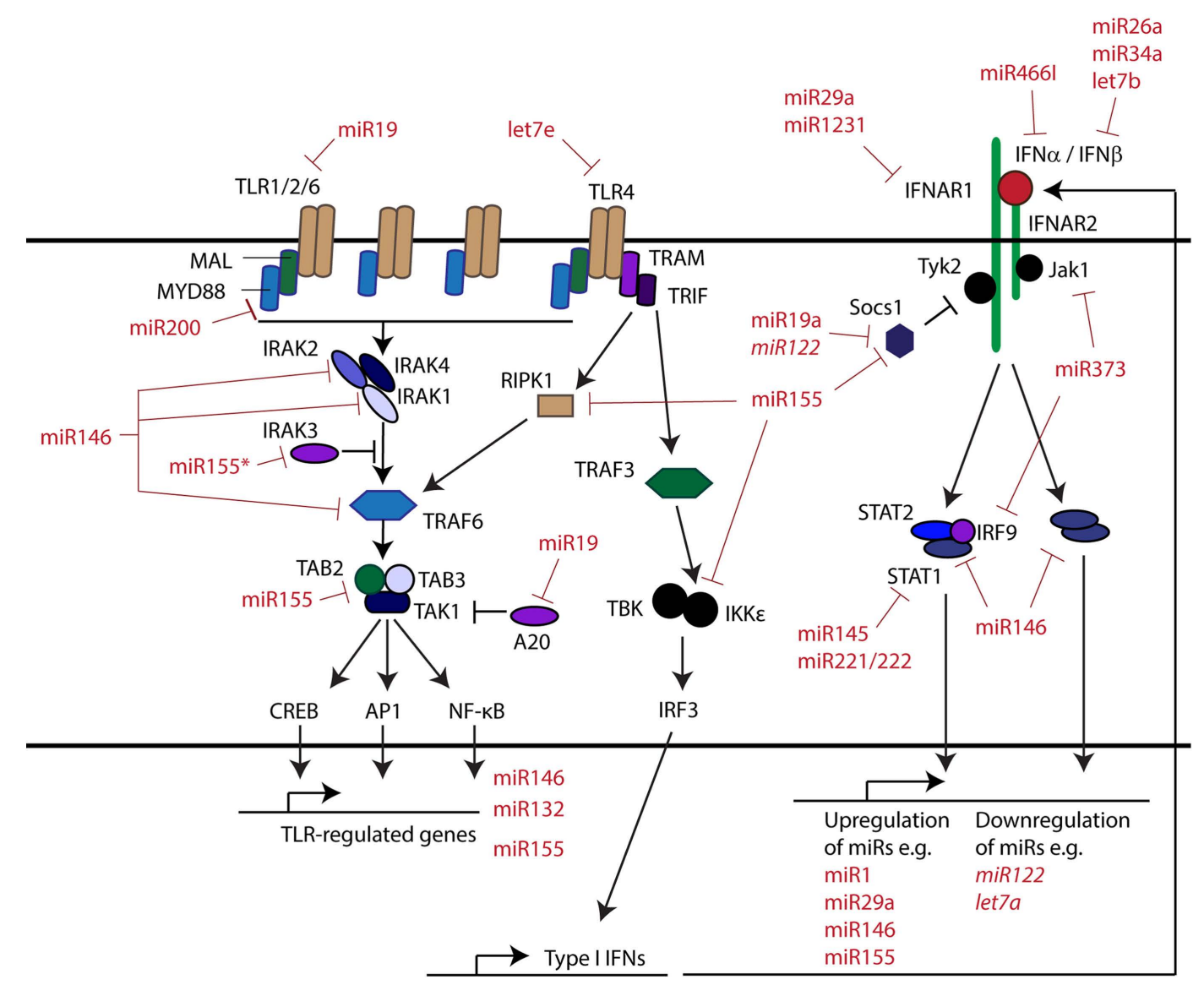

FIGURE 1 | MicroRNAs and their roles in regulating the innate immune response.

At the systems level, an understanding of signaling in the innate immune response has been initiated $(6,7)$. Over the last decade, a role for particular microRNAs and other non-coding RNA in sculpting and modulating many levels of the innate immune response has begun to emerge (8). This includes targeting transcripts encoding components of PRR pathways impacting IFN production, targeting transcripts encoding the IFN cell surface receptors and signal transduction proteins to regulate signaling, and targeting IRGs directly, to shape the overall IFN response. At each of these levels, microRNAs may suppress activation by targeting key signaling components or enhance signaling, by suppressing negative regulators. Interestingly, microRNAs themselves may also be induced or repressed directly through IFN signaling, introducing an additional layer of regulation to this response. This review will highlight the growing body of research in this area.

\section{MicroRNA Biogenesis and Function}

Unlike many families of non-coding RNAs, the processing, accessory proteins and functional requirements for microRNA activity are relatively well understood. Processing from a primary to a mature microRNA occurs through a series of cleavage events dependent on the enzymes Drosha, Dicer, and associated accessory proteins (9). Through this processing, one of the two precursor hairpin RNA strands is incorporated into the RNA-induced silencing complex (RISC) containing the Argonaute (Ago) proteins. These mature microRNA contained within the RISC complex are small, approximately $21-23$ base pair transcripts. Through nucleotide homology, they bind the target messenger RNA (mRNA) molecule, usually within the $3^{\prime}$ untranslated region (UTR), to direct RNA silencing. This silencing has been shown to occur through mRNA cleavage, transcript destabilization by shortening of the mRNA polyadenylated tail, or through direct target degradation (10).

Initial work defining microRNA function has focused largely on constitutively expressed and cell-specific microRNA, assigning to these microRNAs important functions in cell differentiation, lineage commitment, and the determination of cell fate $(11,12)$. High-throughput expression profiling studies of microRNAs in the context of cancer-related diseases, for example, have demonstrated microRNA dysregulation, predominantly reduced expression (13). These observations have led to a model suggesting that microRNAs act primarily in determination of cell fate by guiding differentiation and maintenance of homeostasis. Further experiments using gene profiling have demonstrated a capacity to classify cancers by microRNA expression with many studies investigating the use of microRNAs as circulating biomarkers for prognostic and diagnostic purposes, as recently reviewed in Ref. (14). There is now 
growing knowledge of the role played by microRNA regulation in other biological contexts, including in protecting against infection and regulating the immune response $(8,15)$.

\section{MicroRNA Regulation of Innate Immune Signaling Leading to IFN Production}

Activation of a number of PRR signaling pathways may result in the production of a subset of IFN $\alpha$ subtypes, the single IFN $\beta$ subtype or both a subset of IFN $\alpha$ subtypes and the IFN $\beta$ subtype in combination. While there are no reported stimuli that activate only a single IFN $\alpha$ subtype, nor all IFN $\alpha$, IFN $\beta$ is expressed exclusively in circumstances including M-CSF stimulated macrophage progenitors and RANKL stimulated osteoclast progenitors (16). All IFN subtypes commonly bind the IFNAR receptor complex and activate similar signal transduction pathways, although IFN $\beta$ can also initiate an additional transcriptional response through a unique receptor interaction (17). With increased microRNA expression profiling of innate immune pathways, a growing number of inducible microRNAs are being described that regulate signaling pathways that lead to IFN production. MiR146 and miR155 are two well-described, highly inducible microRNAs, which were initially identified by microarray on human THP-1 cells as responsive to the TLR4 agonist LPS (18). Extensive characterization demonstrates rapid induction of these microRNAs in response to activation of many innate immune pathways, including those initiated by TLR2, TLR4, TLR5, TNF $\alpha$, and IL-1 $\beta$ (18). Fluorescence reporter and microRNA decoy assays have also demonstrated miR146 targeting of TLR signaling molecules, MAL, TRAF6, IRAK1, and IRAK2, which are involved in initiating NF- $\kappa \mathrm{B}$ responses $(19,20)$.

Studies using peripheral blood mononuclear cells (PBMCs) from patients with systemic lupus erythematosus (SLE), a disease commonly associated with excessive type I IFN signaling, identified significant down-regulation of miR146 in PBMCs from patients with this disease (21). Under-expression negatively correlated with clinical disease activity and with IRG expression, while transfection of miR146 transcriptionally suppressed IFN $\alpha$ and IFN $\beta$ expression. In an Epstein-Barr Virus positive lymphoma cell line, miR146 targeted both STAT1 and IRF5 transcripts (21) and resulted in modification of the intensity of the IFN response through suppression of IRGs (22). Given this regulatory relationship, in which miR146 is both induced by NF- $\kappa$ B and acts to negatively regulate NF- $\kappa \mathrm{B}$ and IFN signaling, an important negative feedback relationship is suggested. Indeed, mice lacking miR146 exhibit an autoimmune disease phenotype and over-activation of NF- $\kappa \mathrm{B}$ signaling pathways in a manner consistent with this mode of action $(23,24)$.

Strong up-regulation of miR155 in response to LPS activation of TLR4 is well described $(18,25,26)$. A recent study demonstrated both NF- $\mathrm{\kappa B}$ and ETS2 play a key role in the regulation of miR155 (27). In the context of TLR signaling, western blot and 3' UTR luciferase assays have demonstrated miR155 targeting of TNF adaptor molecules Fas-associated death domain protein (FADD), the serine-threonine kinase Ripk1 and IkappaB kinase epsilon (IKKe) (28), c-Fos (29), the signaling molecule TAB2, and the transcription factor PU.1 (30). Multiple targets within
TLR pathways suggest a role for miR155 in providing protection against uncontrolled TLR responses (28). Significant investigation has also been performed contrasting the actions of the alternate miR155 minor strand during TLR7 signaling (31), suggesting coordinated regulation of the miR155* strand provides a mechanism to modulate IFN production in this response. Rapid up-regulation of miR155* suppresses translation of the negative regulator of TLR signaling, IRAK3, thus potentiating signaling and resulting in greater induction of both $\operatorname{TNF} \alpha$ and $\operatorname{IFN}(31,32)$. This signal enhancement mediated by miR $155^{*}$ contrasts with the buffering role provided by miR155, suggesting a need for further investigation into the expression and activation profiles of the two miR155 strands.

Other microRNAs have been associated with regulating PRR signaling pathways and thus may play important roles in regulation of the IFN response. TLR2 and TLR4 have been shown to be regulated by miR19 (33) and let7e (34), respectively, while the important adaptor molecule MyD88 is targeted by the miR200 family (35). Since the pathways in which these receptors and adaptor are found are involved in the induction of IFN gene expression, these microRNAs may thus impact on IFN production, but this has not been directly shown. These data together suggest a complex regulatory network interacting to balance the degree and duration of the TLR and thus IFN responses.

Multiple members of the IFN $\alpha$ gene family have been shown to be directly targeted by miR466i at the transcript level, reducing IFN production by macrophages and dendritic cells, as well as the induction of an anti-viral response (36). Similarly, miR26a, miR34a, and let7b directly target the IFN $\beta$ gene transcript. Interestingly, IFN $\beta$ signaling was shown to up-regulate the expression of these microRNAs, indicating a potential negative feedback loop to buffer IFN $\beta$ production (37). Overall, these studies demonstrate an important, emerging role for microRNA regulation of IFN production, which may be applied directly through targeting IFN transcripts or indirectly through subtle manipulations of the strength, timing, and duration of the upstream PRR signaling pathways.

\section{MicroRNA Regulation of Type I IFN Signaling}

In addition to impacting IFN production through targeting PRRs, there is mounting evidence that microRNAs also directly regulate different aspects of the type I IFN signaling pathway. Type I IFNs bind to the cell surface IFNAR receptor complex, comprised of the subunits IFNAR1 and IFNAR2, resulting in phosphorylation and activation of the associated tyrosine kinases TYK2 and JAK1 (Figure 1). These in turn phosphorylate receptor tyrosine residues leading to the recruitment and activation of transcription factors. These transcription factors include STAT1, STAT3, and STAT5 homo- and heterodimers, the ISGF3 complex, composed of STAT1, STAT2, and IRF9, as well as STAT-independent pathways (16).

At the type I IFN receptor level, multiple microRNAs have been reported to target IFNAR1. MiR29a has been shown experimentally to reduce the expression of IFNAR1 on murine thymic epithelial cells, reducing IFN responses critical in the regulation 
of thymic cellularity (38). In this study, mice lacking miR29a displayed increased thymic IFNAR1 expression and hyper-sensitivity to polyI:C treatment. A single nucleotide polymorphism (SNP) ablating miR1231 regulation of IFNAR1 has been associated as a causative factor in hepatocellular carcinoma (39). MicroRNAs can also indirectly modulate type I IFN signal transduction by targeting SOCS1, a negative regulator of the JAK-STAT pathway, which binds the receptor complex through interaction with TYK2 (40). MiR19a, miR122, and miR155 have been shown to target SOCS1, resulting in enhancement of type I IFN signaling and subsequent innate and adaptive immune responses (41-45). This miR155 targeting of SOCS1 is consistent with increased phosphorylation of STAT1 and STAT3, resulting in the enhanced induction of antiviral genes and inhibition of HBV replication (46).

Downstream of the IFN receptor, STAT1, STAT2, and STAT5 are targeted by a number of microRNAs, as reviewed previously (47). In particular, STAT1 is targeted by miR145, miR146, and miR221/222, and STAT2 by miR221/222, reducing type I IFN signaling and IRG expression. A recent study also illustrated that miR373 reduces the expression of both JAK1 and IRF9, leading to reduced type I IFN anti-viral gene induction and increased HCV replication (48). STAT3 regulation by microRNAs, including miR9, miR93, miR20a, and miR17, has also been examined in many disease and developmental contexts, as previously reviewed in Ref. (49). In the context of IFN response, the direct regulation of STAT3 remains to be elucidated.

\section{IFN Regulation of MicroRNAs}

While extensive characterization of the microRNA response to type I IFN examining temporal or subtype variation has not been reported, analysis using microarray based expression profiling has provided some insight into IFN-regulated microRNAs. Characterization of IFN $\beta$-regulated microRNAs in Huh7 cells, with a custom microarray containing 245 microRNAs from humans and mice, identified 30 microRNAs that were induced or suppressed (50). Interestingly, these included eight induced microRNAs (miR1, miR30, miR128, miR196, miR296, miR351, miR431, and miR448) that displayed complementarity in their seed sequences with hepatitis $\mathrm{C}$ virus RNA. In addition, miR122, which positively regulates HCV replication, was suppressed by IFN $\beta$. MiR122 acts to enhance viral replication by shielding the HCV genome from the cytosolic RNA exonuclease, Xrn1 mediated degradation, and another, yet undefined, Xrn1 independent mechanism (51). Other studies in human glioma cells stimulated with IFN $\beta$ used more advanced microarrays containing 662 probes. These experiments identified induction of miR187 and miR194 and suppression of miR100, let7a, let7b, let7c, and miR21 (52). In total, 36 type I IFN-regulated microRNAs have been reported to date using arrays and quantitative real-time PCR (Table 1). Of these, 18 are regulated by IFN $\beta, 14$ by IFN $\alpha$, and 4 have been shown to be regulated by both IFN $\beta$ and IFN $\alpha$. While 21 microRNAs are reported to be up-regulated after IFN stimulation, 13 are suppressed. Let7b and miR30 are regulated differentially in a cell type-specific manner $(50,53,54)$. Interestingly, this list includes a number of key microRNAs already described as playing important roles in regulating the induction of type I IFNs. Notably, miR155, induced broadly and
TABLE 1 | Table of known IFN-regulated microRNAs.

\begin{tabular}{|c|c|c|c|c|c|}
\hline MicroRNA & Stimulation & $\begin{array}{l}\text { Cell type/ } \\
\text { tissue }\end{array}$ & Change & Technique & Reference \\
\hline Let7a & IFN $\beta$ & Glioma & Down & Microarray & (52) \\
\hline \multirow[t]{2}{*}{ Let7b } & $\mathrm{IFN} \alpha$ & Huh7 & Up & Microarray & (55) \\
\hline & IFN $\beta$ & Glioma & Down & Microarray & (52) \\
\hline Let7c & IFN $\beta$ & Glioma & Down & Microarray & (52) \\
\hline Let7f & $\mathrm{IFN} \alpha$ & Huh7 & Up & Microarray & (55) \\
\hline \multirow[t]{3}{*}{ miR1 } & $\mathrm{IFN} \alpha$ & PBMC & Up & RT-PCR & (53) \\
\hline & $\mathrm{IFN} \beta$ & Huh7 & Up & $\begin{array}{l}\text { Microarray, } \\
\text { RT-PCR }\end{array}$ & $(50,56)$ \\
\hline & & $\begin{array}{l}\text { Primary } \\
\text { hepatocyte }\end{array}$ & Up & RT-PCR & (50) \\
\hline miR100 & $\mathrm{IFN} \beta$ & Glioma & Down & Microarray & (52) \\
\hline miR122 & IFN $\beta$ & Huh7 & Down & Microarray & (50) \\
\hline miR1225 & $\mathrm{IFN} \alpha$ & Huh7 & Down & Microarray & (55) \\
\hline \multirow[t]{2}{*}{$\operatorname{miR} 128$} & $\mathrm{IFN} \alpha$ & PBMC & Up & RT-PCR & (53) \\
\hline & $\mathrm{IFN} \beta$ & Huh7 & Up & $\begin{array}{l}\text { Microarray, } \\
\text { RT-PCR }\end{array}$ & $(50,56)$ \\
\hline miR129 & $\mathrm{IFN} \beta$ & HeLa & Up & $\begin{array}{l}\text { Microarray } \\
\text { RT-PCR }\end{array}$ & (57) \\
\hline miR1296 & $\mathrm{IFN} \alpha$ & Huh7 & Down & Microarray & (55) \\
\hline $\operatorname{miR} 142$ & $\mathrm{IFN} \beta$ & Huh7 & Up & RT-PCR & (56) \\
\hline miR143 & $\mathrm{IFN} \alpha$ & Huh7 & Up & Microarray & (55) \\
\hline miR146 & $\mathrm{IFN} \beta$ & Huh7 & Up & RT-PCR & (56) \\
\hline \multirow[t]{4}{*}{ miR155 } & IFN $\beta$ & $\mathrm{BMM}$ & Up & Microarray & (26) \\
\hline & IFN $\beta$ & RAW264.7 & Up & RT-PCR & (58) \\
\hline & $\mathrm{IFN} \beta$ & Huh7 & Up & $\begin{array}{l}\text { RT-PCR, } \\
\text { Microarray }\end{array}$ & $(50,56)$ \\
\hline & & $\begin{array}{l}\text { Primary } \\
\text { hepatocyte }\end{array}$ & Up & RT-PCR & (50) \\
\hline miR181a & $\mathrm{IFN} \alpha$ & Huh7 & Up & Microarray & (55) \\
\hline miR184 & $\mathrm{IFN} \alpha$ & Huh7 & Down & Microarray & (55) \\
\hline miR187 & IFN $\beta$ & Glioma & Up & Microarray & (52) \\
\hline miR190b & $\mathrm{IFN} \alpha$ & Huh7 & Down & Microarray & (55) \\
\hline miR194 & IFN $\beta$ & Glioma & Up & Microarray & (52) \\
\hline miR195 & $\mathrm{IFN} \beta$ & $L X-2$ & Up & RT-PCR & (59) \\
\hline miR196a & IFN $\beta$ & Huh7 & Up & RT-PCR & (56) \\
\hline miR21 & $\mathrm{IFN} \beta$ & Glioma & Down & Microarray & (52) \\
\hline miR212 & $\mathrm{IFN} \alpha$ & Huh7 & Down & Microarray & (55) \\
\hline \multirow[t]{2}{*}{ miR296 } & $\mathrm{IFN} \beta$ & Huh7 & Down & RT-PCR & (56) \\
\hline & IFN $\beta$ & Huh7 & Down & Microarray & (50) \\
\hline \multirow[t]{3}{*}{ miR30 } & $\mathrm{IFN} \alpha$ & PBMC & Up & RT-PCR & (53) \\
\hline & $\mathrm{IFN} \alpha$ & $\begin{array}{l}\text { Blood-derived } \\
\text { human NK } \\
\text { cells }\end{array}$ & Down & Sequencing & (54) \\
\hline & IFN $\beta$ & Huh7 & Up & $\begin{array}{l}\text { Microarray, } \\
\text { RT-PCR }\end{array}$ & $(50,56)$ \\
\hline miR301 & $\mathrm{IFN} \alpha$ & Huh7 & Up & Microarray & (55) \\
\hline miR34a & IFN $\beta$ & & Up & & (60) \\
\hline miR351 & IFN $\beta$ & Huh7 & Up & Microarray & (50) \\
\hline miR378 & $\mathrm{IFN} \alpha$ & $\begin{array}{l}\text { Blood- } \\
\text { derived } \\
\text { human NK } \\
\text { cells }\end{array}$ & Down & Sequencing & (54) \\
\hline $\operatorname{miR} 431$ & IFN $\beta$ & Huh7 & Up & Microarray & (50) \\
\hline miR448 & IFN $\beta$ & Huh7 & Up & Microarray & (50) \\
\hline miR449a & $\mathrm{IFN} \alpha$ & Huh7 & Down & Microarray & (55) \\
\hline miR499a & $\mathrm{IFN} \alpha$ & Huh7 & Up & Microarray & (55) \\
\hline miR518b & $\mathrm{IFN} \alpha$ & Huh7 & Down & Microarray & (55) \\
\hline miR582 & $\mathrm{IFN} \alpha$ & Huh7 & Up & Microarray & (55) \\
\hline
\end{tabular}

List of reported IFN-regulated microRNAs, identified through specific cellular stimulation with type / IFN. 
strongly in response to IFN, has been shown to both suppress TLR signaling and induce IFN signaling through targeting of SOCS1 (42). This regulation may occur in a cell type-specific manner or act within the same cell to induce a shift to suppress TLR-based signaling and enhance IFN signaling, once the secondary signal has been induced. Alternatively, miR155 induction by IFN in a cell where TLR induction has not yet occurred could render a cell unresponsive to TLR signaling and focus cell resources into the induction of an IFN-mediated protective state. Overall, the existing data suggest a negative regulatory role for the major miR155 strand in buffering TLR signaling that may be induced either through NF- $\kappa \mathrm{B}$ signaling or downstream of IFN signaling. This contrasts the role for the minor miR $155^{\star}$ strand in enhancing IFN signaling through negative regulation of IRAK3, described previously, suggesting an important miR155 dependent switch in immune response.

IFN $\beta$ is currently used as a therapy for multiple sclerosis (MS). In about $85 \%$ of patients, disease associated with MS starts with a single demyelinating episode (clinically isolated syndrome, CIS), which progresses to a relapsing-remitting course (RRMS) with acute exacerbations and periods of remission. A study by Hecker et al. longitudinally examined microRNA expression profiles in PBMCs from patients with CIS or RRMS in response to subcutaneous IFN $\beta$ therapy (61). Microarray analysis demonstrated seven microRNAs were up-regulated (e.g., let7a, let7b) and 13 microRNAs were down-regulated (e.g., miR29a, miR29c) following IFN $\beta$ treatment. Consistent with these results, miR29 has been identified in our unpublished studies as up-regulated early by IFN $\beta$, yet down-regulated by $48 \mathrm{~h}$. Given the known role of miR29 targeting IFNAR1, this regulatory relationship suggests a negative feedback role in limiting the type I IFN response. Such a relationship would provide a capacity for a cell to rapidly induce the IFN response, while providing innate protection against the detrimental impacts of over-activation or an inappropriately sustained response.

\section{IFN Regulation of MicroRNA Machinery}

In addition to direct regulation of microRNAs by IFN, modulation of the microRNA processing machinery would be predicted to have wide-scale impacts on the overall biological outcome. Examination of IFN-mediated transcript regulation through analysis with the Interferome database (a global collection of IRGs) (5) suggests strong down-regulation by more than threefold in both Ago 1 and Ago 2 in lung and blood cells $24 \mathrm{~h}$ following IFN $\alpha$ treatment $(62,63)$. Emerging evidence suggests that microRNA may have differential association with the various Argonaute family members (64). This relationship introduces a possibility that differential down-regulation of Ago proteins may act as an additional IFN-induced, regulatory mechanism. In the absence of Agol and 2, it could be expected that IFN stimulation would favor activity of microRNAs that predominantly interact with Ago 3 and Ago4. In addition to the Argonaute protein regulation, evidence exists for post-transcriptional Dicer down-regulation with prolonged IFN stimulation. Using Western blot, Weisen et al. demonstrated that both IFN $\alpha$ and polyI:C stimulation could lead to down-regulation of Dicer after $72 \mathrm{~h}$ (65). These longer-term regulatory impacts of the type I IFN response on the microRNA cellular machinery suggest a biphasic response in which early microRNA regulation plays a key role in determining cellular responses and protection. By contrast, longer-term suppression of microRNA regulation may provide a benefit by preventing hijacking of the system by pathogen-derived microRNA. In addition to broad scale changes in regulatory machinery, specific changes in microRNA targeting may be controlled through the adenosine deaminase (ADAR) or apolipoprotein B mRNA editing enzyme, catalytic polypeptide (Apobec) families of proteins, both of which are induced strongly by IFN. ADAR family members, particularly, are widely reported to direct microRNA regulation through transcript editing and warrant further investigations in an IFN context (66).

\section{Interferon Regulation of Anti-Viral MicroRNAs}

The anti-viral functions of effector proteins induced during the IFN response are well understood and studies now focus on the role of IFN-induced microRNAs in direct targeting of viral transcripts $(50,67)$. It is hypothesized that this could occur in a manner similar to the well-characterized, RNAi-based, plant anti-viral defense system (68). While this hypothesis remains contentious, growing evidence exists for direct viral targeting by cellular microRNAs. This includes investigations in viral infections, including hepatitis B (69), hepatitis C $(50,70)$, and HIV (71). These studies have identified miR122 as targeting hepatitis B and C and miR29 as targeting HIV; both miR122 and miR29 have been reported previously as IFN-regulated microRNAs. These data suggest that IFN-induced microRNAs may directly target viral RNA in addition to modifying the cellular state through regulation of host anti-viral genes. This targeting strategy is also being investigated for the development of experimental vaccines against influenza A virus. Through the insertion of mammalian-specific microRNA target sites in the viral genome, egg-produced live viruses can be rendered attenuated through microRNA silencing in mammalian vaccine recipients (72). The breadth of IFN-regulated host microRNAs that may directly target viral RNA remains to be determined.

\section{Identification of MicroRNA Targets}

To further understand the role of known IFN-regulated microRNAs and those which regulate the IFN response, predicting the structure and functional significance of regulatory networks, identifying novel microRNAs, and understanding the targeting relationships is critical. Accurate computational prediction of microRNA regulation remains limited and represents an active area of research. In 2005, Brenecke et al. characterized three classes of microRNA binding (73):

1. Canonical binding involved high complementarity throughout the sequence with exact complementarity observed within the last six to eight base pairs of the $5^{\prime}$ end of the microRNA, termed the "seed" region.

2. $5^{\prime}$ dominant seed region binding was defined where the seed region exhibited high complementarity, while the remaining 
microRNA had limited complementarity with the target region.

3. $3^{\prime}$ compensatory binding was described in which binding in the $3^{\prime}$ region can compensate for mismatches in the $5^{\prime}$ seed region (73).

These definitions were further expanded in 2009, resulting in the definition of seven types of sites: five based on seed region complementarity resulting in seed based binding sites plus two additional categories, $3^{\prime}$ supplementary and $3^{\prime}$ compensatory (74). The seed-based matches are composed of three canonical sites that vary in length from seven to eight base pairs and differ by the association with an adenine at the $5^{\prime}$ end of the microRNA (75). A further two seed-based sites with a six base pair region complementarity have also been identified; however, due to their frequency, these are rarely detected using algorithmic approaches. The $3^{\prime}$ site categories remain similar to those previously defined, with supplementary sites containing consecutive base pair complementarity at the $3^{\prime}$ end. In the $3^{\prime}$ compensatory category, binding in the $3^{\prime}$ region acts to negate mismatches in the seed region. Indeed, many studies have now shown conclusively that binding is more complex than simple seed region recognition. Fluorescence reporter assays have been applied to validate seedless target recognition, while sequence-based, high-throughput target validation has demonstrated the diversity of these interactions (76-79).

As the definitions of these sites have improved, the availability and diversity of algorithms for their detection have also increased. Algorithms for microRNA target site identification include miRanda (80), Dianna-microT (81), PicTar (82), PITA (83), and RNA22 (84). Despite this diversity of algorithms, the ability to predict targets that can be experimentally validated is limited, with a high frequency of false positive results being the common problem. Indeed, comprehensive algorithm comparisons suggest sensitivity rates, defined as the number of correctly predicted sites as a proportion of total correct sites, to vary between 6 and $20 \%$ depending on the algorithm applied (85). Equally, precision, defined as the number of correct predictions as a proportion of the total predicted, ranged from 24 to $51 \%$ (85). Given the resource investment associated with experimental validation of these interactions, such a poor accuracy rate in computational predictions represents a significant area of concern. These numbers, however, have not been reliably and extensively determined specifically for microRNAs involved in innate immune or IFN responses. As such, for these biological systems, the breadth of IFN-regulated microRNA target networks remains to be determined.

Wide-scale experimental mapping of microRNA binding sites is emerging as the solution to these limitations. These methods include PAR-CLIP (86), HITS-CLIP (87) and CLASH (88), which involve UV or chemical crosslinking, and the use of antibody based methods to pull down the RISC complex and associated microRNAs, and target transcript RNAs. When combined with high-throughput sequencing, the resulting samples can provide a detailed overview of microRNA binding to a target within a cell. While much like early chromatin immunoprecipitation-based transcription factor analysis, antibody efficiency and protocol sensitivities currently limit widespread adoption of these techniques.
Nevertheless, these methods provide great potential for future understanding of microRNA networks and their regulation.

\section{MicroRNA Targeting of IFN-Regulated Genes}

While there are limited direct studies of IFN-regulated microRNA targeting of IRGs, one of the first applications of the HITS-CLIP approach compared activated $\mathrm{CD}^{+} \mathrm{T}$-cells in wild-type and miR155 knockout cells from mice, and provided indirect evidence that this microRNA targeted IRGs (79). This analysis identified 4195 genes containing Ago-binding sites, of which 175 genes were predicted to be regulated by miR155. This analysis identified microRNA binding sites previously predicted by computational methods, but approximately $40 \%$ of the experimentally identified sites lacked perfect seed complementarity, and thus could not have been predicted computationally. Interestingly, meta-analysis of the 175 genes predicted to be regulated by miR155 included 82 genes that were contained within the Interferome database (5) as IRGs (1.5-fold cutoff). Analysis of this first set of immune-related microRNA targeting relationships supports a role for inducible miR155 targeting, suggesting that miR155 acts as both as an IFN inducible microRNA and a negative regulator of the type I IFN response in the context of CD4 ${ }^{+} \mathrm{T}$-cell activation (79). Microarray based correlation analyses have also suggested a relationship between IFN $\beta$ inducible miR128, miR196a, or miR142 with reported IRGs HNMT, XPO1, PMPCB, and HMGB1 (56). However, evidence of multiple microRNA directly targeting IRGs remains to be presented. As these RNA-immunoprecipitation based technologies become more readily available, examination of the type I IFN response, specifically, and the innate immune response, more broadly, will elucidate the importance of microRNA targeting as a component of these responses.

\section{Summary, Conclusion, and Future Directions}

Recent studies have shown an important role for microRNAs in regulating the innate and adaptive immune response, and key cytokines in these responses, including the type I IFNs. There are examples of microRNA regulation at many stages of the IFN response, namely through regulation of components of PRR signaling that drive IFN expression; their cognate receptor components, IFNAR1 and IFNAR2; down-stream signal transduction pathways including STATs; and through association with IRGs themselves. There are currently 36 microRNAs reported to be regulated by type I IFNs; but with improvements in sequencing technologies, we can expect this number to grow substantially (as we have seen in unpublished studies). Not only do IFN-regulated microRNAs target components of the IFN response to modulate its biological effects, such as anti-viral actions, they can also directly target viral RNA. In addition to regulating the transcription of microRNAs, IFN may also show unique regulation of microRNA processing by regulation of Dicer, Ago, and editing proteins, which are themselves IRGs. Thus, part of the IFN response may be a general impact on microRNA processing. Advances in technologies such 
as CLIP, combined with RNA sequencing, will enable the further definition of the breadth of microRNA regulation of IFN responses in different contexts. Given the capacity of microRNA networks to "buffer' responses, their modulation may open new therapeutic opportunities. Finally, given the use of microRNA detection as biomarkers in cancer, there may be similar opportunities in inflammatory diseases and numerous previously described IFN-mediated conditions, including autoimmune diseases such as SLE and MS.

\section{Author Contributions}

SF, MT, and PH all made substantial contributions to the conception and writing of this review. They all provided different components of the important intellectual content, approve this

\section{References}

1. O'Neill LA, Golenbock D, Bowie AG. The history of toll-like receptors - redefining innate immunity. Nat Rev Immunol (2013) 13(6):453-60. doi:10.1038/nri3446

2. Maekawa T, Kufer TA, Schulze-Lefert P. NLR functions in plant and animal immune systems. So far and yet so close. Nat Immunol (2011) 12(9):817-26. doi:10.1038/ni.2083

3. Loo YM, Gale M Jr. Immune signaling by RIG-I-like receptors. Immunity (2011) 34(5):680-92. doi:10.1016/j.immuni.2011.05.003

4. Forster S. Interferon signatures in immune disorders and disease. Immunol Cell Biol (2012) 90(5):520-7. doi:10.1038/icb.2012.12

5. Rusinova I, Forster S, Yu S, Kannan A, Masse M, Cumming H, et al. Interferome v2.0: an updated database of annotated interferon-regulated genes. Nucleic Acids Res (2013) 41(Database issue):D1040-6. doi:10.1093/nar/gks1215

6. Oda K, Kitano H. A comprehensive map of the toll-like receptor signaling network. Mol Syst Biol (2006) 2:2006.0015. doi:10.1038/msb4100057

7. Hertzog P, Forster S, Samarajiwa S. Systems biology of interferon responses. J Interferon Cytokine Res (2011) 31(1):5-11. doi:10.1089/jir.2010.0126

8. Lee HM, Nguyen DT, Lu LF. Progress and challenge of microRNA research in immunity. Front Genet (2014) 5:178. doi:10.3389/fgene.2014.00178

9. Ha M, Kim VN. Regulation of microRNA biogenesis. Nat Rev Mol Cell Biol (2014) 15(8):509-24. doi:10.1038/nrm3838

10. Huntzinger E, Izaurralde E. Gene silencing by microRNAs. contributions of translational repression and mRNA decay. Nat Rev Genet (2011) 12(2):99-110. doi:10.1038/nrg2936

11. Ivey KN, Srivastava D. MicroRNAs as regulators of differentiation and cell fate decisions. Cell Stem Cell (2010) 7(1):36-41. doi:10.1016/j.stem.2010.06.012

12. Iorio MV, Croce CM. Causes and consequences of microRNA dysregulation. Cancer J (2012) 18(3):215-22. doi:10.1097/PPO.0b013e318250c001

13. Lu J, Getz G, Miska EA, Alvarez-Saavedra E, Lamb J, Peck D, et al. MicroRNA expression profiles classify human cancers. Nature (2005) 435(7043):834-8. doi: $10.1038 /$ nature 03702

14. Schwarzenbach H, Nishida N, Calin GA, Pantel K. Clinical relevance of circulating cell-free microRNAs in cancer. Nat Rev Clin Oncol (2014) 11(3):145-56. doi:10.1038/nrclinonc.2014.5

15. Sedger LM. MicroRNA control of interferons and interferon induced anti-viral activity. Mol Immunol (2013) 56(4):781-93. doi:10.1016/j.molimm.2013.07.009

16. Hertzog PJ, Williams BR. Fine tuning type I interferon responses. Cytokine Growth Factor Rev (2013) 24(3):217-25. doi:10.1016/j.cytogfr.2013.04.002

17. de Weerd NA, Vivian JP, Nguyen TK, Mangan NE, Gould JA, Braniff SJ, et al. Structural basis of a unique interferon-beta signaling axis mediated via the receptor IFNAR1. Nat Immunol (2013) 14(9):901-7. doi:10.1038/ni.2667

18. Taganov KD, Boldin MP, Chang KJ, Baltimore D. NF-kappaB-dependent induction of microRNA miR-146, an inhibitor targeted to signaling proteins of innate immune responses. Proc Natl Acad Sci U S A (2006) 103(33):12481-6. doi:10.1073/pnas.0605298103

19. Hou J, Wang P, Lin L, Liu X, MaF, An H, et al. MicroRNA-146a feedbackinhibits RIGI-dependent Type I IFN production in macrophages by targeting TRAF6, IRAK1, and IRAK2. J Immunol (2009) 183(3):2150-8. doi:10.4049/jimmunol.0900707 version of the article for publication, agree to be accountable for all aspects of the work, and will ensure that questions related to the accuracy or integrity of any part of the work are appropriately investigated and resolved.

\section{Acknowledgments}

The authors are supported by a C.J. Martin Fellowship (SF, 1091097), a Peter Doherty Fellowship (MT, 1035733), and a Senior Principal Research Fellowship (PH, 1027020), all awarded by the Australian National Health and Medical Research Council. The authors acknowledge the support of the Victorian Government's Operational Infrastructure Support Program and Dr. Rebecca Smith for her assistance in preparing the manuscript.

20. Starczynowski DT, Kuchenbauer F, Wegrzyn J, Rouhi A, Petriv O, Hansen CL, et al. MicroRNA-146a disrupts hematopoietic differentiation and survival. Exp Hematol (2011) 39(2):167-178.e4. doi:10.1016/j.exphem.2010.09.011

21. Tang Y, Luo X, Cui H, Ni X, Yuan M, Guo Y, et al. MicroRNA-146A contributes to abnormal activation of the type I interferon pathway in human lupus by targeting the key signaling proteins. Arthritis Rheum (2009) 60(4):1065-75. doi:10.1002/art.24436

22. Cameron JE, Yin Q, Fewell C, Lacey M, McBride J, Wang X, et al. Epstein-Barr virus latent membrane protein 1 induces cellular MicroRNA miR-146a, a modulator of lymphocyte signaling pathways. J Virol (2008) 82(4):1946-58. doi:10.1128/ JVI.02136-07

23. Boldin MP, Taganov KD, Rao DS, Yang L, Zhao JL, Kalwani M, et al. miR-146a is a significant brake on autoimmunity, myeloproliferation, and cancer in mice. J Exp Med (2011) 208(6):1189-201. doi:10.1084/jem.20101823

24. Zhao JL, Rao DS, Boldin MP, Taganov KD, O'Connell RM, Baltimore D. NF-kappaB dysregulation in microRNA-146a-deficient mice drives the development of myeloid malignancies. Proc Natl Acad Sci US A (2011) 108(22):9184-9. doi:10.1073/pnas.1105398108

25. Tili E, Michaille JJ, Gandhi V, Plunkett W, Sampath D, Calin GA. miRNAs and their potential for use against cancer and other diseases. Future Oncol (2007) 3(5):521-37. doi:10.2217/14796694.3.5.521

26. O'Connell RM, Taganov KD, Boldin MP, Cheng G, Baltimore D. MicroRNA-155 is induced during the macrophage inflammatory response. Proc Natl Acad Sci U $S$ A (2007) 104(5):1604-9. doi:10.1073/pnas.0610731104

27. Quinn SR, Mangan NE, Caffrey BE, Gantier MP, Williams BR, Hertzog PJ, et al. The role of Ets2 transcription factor in the induction of microRNA-155 (miR-155) by lipopolysaccharide and its targeting by interleukin-10. J Biol Chem (2014) 289(7):4316-25. doi:10.1074/jbc.M113.522730

28. Tili E, Michaille JJ, Cimino A, Costinean S, Dumitru CD, Adair B, et al. Modulation of miR-155 and miR-125b levels following lipopolysaccharide/TNF-alpha stimulation and their possible roles in regulating the response to endotoxin shock. J Immunol (2007) 179(8):5082-9. doi:10.4049/jimmunol.179.8.5082

29. Dunand-Sauthier I, Santiago-Raber ML, Capponi L, Vejnar CE, Schaad O, Irla M, et al. Silencing of c-Fos expression by microRNA-155 is critical for dendritic cell maturation and function. Blood (2011) 117(17):4490-500. doi:10.1182/ blood-2010-09-308064

30. Martinez-Nunez RT, Louafi F, Friedmann PS, Sanchez-Elsner T. MicroRNA-155 modulates the pathogen binding ability of dendritic cells (DCs) by down-regulation of DC-specific intercellular adhesion molecule-3 grabbing non-integrin (DC-SIGN). J Biol Chem (2009) 284(24):16334-42. doi:10.1074/jbc.M109.011601

31. Zhou H, Huang X, Cui H, Luo X, Tang Y, Chen S, et al. miR-155 and its starform partner miR-155* cooperatively regulate type I interferon production by human plasmacytoid dendritic cells. Blood (2010) 116(26):5885-94. doi:10.1182/ blood-2010-04-280156

32. Kobayashi K, Hernandez LD, Galan JE, Janeway CA Jr, Medzhitov R, Flavell RA. IRAK-M is a negative regulator of toll-like receptor signaling. Cell (2002) 110(2):191-202. doi:10.1016/S0092-8674(02)00827-9

33. Philippe L, Alsaleh G, Suffert G, Meyer A, Georgel P, Sibilia J, et al. TLR2 expression is regulated by microRNA miR-19 in rheumatoid fibroblast-like synoviocytes. J Immunol (2012) 188(1):454-61. doi:10.4049/jimmunol.1102348 
34. Androulidaki A, Iliopoulos D, Arranz A, Doxaki C, Schworer S, Zacharioudaki V, et al. The kinase Aktl controls macrophage response to lipopolysaccharide by regulating microRNAs. Immunity (2009) 31(2):220-31. doi:10.1016/j. immuni.2009.06.024

35. Wendlandt EB, Graff JW, Gioannini TL, McCaffrey AP, Wilson ME. The role of microRNAs miR-200b and miR-200c in TLR4 signaling and NF-kappaB activation. Innate Immun (2012) 18(6):846-55. doi:10.1177/1753425912443903

36. Li Y, Fan X, He X, Sun H, Zou Z, Yuan H, et al. MicroRNA-466l inhibits antiviral innate immune response by targeting interferon-alpha. Cell Mol Immunol (2012) 9(6):497-502. doi:10.1038/cmi.2012.35

37. Witwer KW, Sisk JM, Gama L, Clements JE. MicroRNA regulation of IFN-beta protein expression: rapid and sensitive modulation of the innate immune response. J Immunol (2010) 184(5):2369-76. doi:10.4049/jimmunol.0902712

38. Papadopoulou AS, Dooley J, Linterman MA, Pierson W, Ucar O, Kyewski B, et al. The thymic epithelial microRNA network elevates the threshold for infection-associated thymic involution via miR-29a mediated suppression of the IFN-alpha receptor. Nat Immunol (2012) 13(2):181-7. doi:10.1038/ni.2193

39. Zhou C, Yu Q, Chen L, Wang J, Zheng S, Zhang J. A miR-1231 binding site polymorphism in the 3'UTR of IFNAR1 is associated with hepatocellular carcinoma susceptibility. Gene (2012) 507(1):95-8. doi:10.1016/j.gene.2012.06.073

40. Piganis RA, De Weerd NA, Gould JA, Schindler CW, Mansell A, Nicholson SE, et al. Suppressor of cytokine signaling (SOCS) 1 inhibits type I interferon (IFN) signaling via the interferon alpha receptor (IFNAR1)-associated tyrosine kinase Tyk2. J Biol Chem (2011) 286(39):33811-8. doi:10.1074/jbc.M111.270207

41. Jiang S, Zhang HW, Lu MH, He XH, Li Y, Gu H, et al. MicroRNA-155 functions as an OncomiR in breast cancer by targeting the suppressor of cytokine signaling 1 gene. Cancer Res (2010) 70(8):3119-27. doi:10.1158/0008-5472.CAN-09-4250

42. Wang P, Hou J, Lin L, Wang C, Liu X, Li D, et al. Inducible microRNA-155 feedback promotes type I IFN signaling in antiviral innate immunity by targeting suppressor of cytokine signaling 1. J Immunol (2010) 185(10):6226-33. doi:10.4049/jimmunol.1000491

43. Li A, Song W, Qian J, Li Y, He J, Zhang Q, et al. MiR-122 modulates type I interferon expression through blocking suppressor of cytokine signaling 1. Int J Biochem Cell Biol (2013) 45(4):858-65. doi:10.1016/j.biocel.2013.01.008

44. Yao R, Ma YL, Liang W, Li HH, Ma ZJ, Yu X, et al. MicroRNA-155 modulates Treg and Th17 cells differentiation and Th17 cell function by targeting SOCS1. PLoS One (2012) 7(10):e46082. doi:10.1371/journal.pone.0046082

45. Pichiorri F, Suh SS, Ladetto M, Kuehl M, Palumbo T, Drandi D, et al. MicroRNAs regulate critical genes associated with multiple myeloma pathogenesis. Proc Natl Acad Sci U S A (2008) 105(35):12885-90. doi:10.1073/pnas.0806202105

46. Su C, Hou Z, Zhang C, Tian Z, Zhang J. Ectopic expression of microRNA-155 enhances innate antiviral immunity against $\mathrm{HBV}$ infection in human hepatoma cells. Virol J (2011) 8:354. doi:10.1186/1743-422X-8-354

47. Kohanbash G, Okada H. MicroRNAs and STAT interplay. Semin Cancer Biol (2012) 22(1):70-5. doi:10.1016/j.semcancer.2011.12.010

48. Mukherjee A, Di Bisceglie AM, Ray RB. Hepatitis C virus-mediated enhancement of microRNA miR-373 impairs the JAK/STAT signaling pathway. J Virol (2015) 89(6):3356-65. doi:10.1128/JVI.03085-14

49. Haghikia A, Hoch M, Stapel B, Hilfiker-Kleiner D. STAT3 regulation of and by microRNAs in development and disease. JAKSTAT (2012) 1(3):143-50. doi:10.4161/jkst.19573

50. Pedersen IM, Cheng G, Wieland S, Volinia S, Croce CM, Chisari FV, et al. Interferon modulation of cellular microRNAs as an antiviral mechanism. Nature (2007) 449(7164):919-22. doi:10.1038/nature06205

51. Li Y, Masaki T, Yamane D, McGivern DR, Lemon SM. Competing and noncompeting activities of miR-122 and the 5' exonuclease Xrn1 in regulation of hepatitis C virus replication. Proc Natl Acad Sci U S A (2013) 110(5):1881-6. doi:10.1073/ pnas. 1213515110

52. Ohno M, Natsume A, Kondo Y, Iwamizu H, Motomura K, Toda H, et al. The modulation of microRNAs by type I IFN through the activation of signal transducers and activators of transcription 3 in human glioma. Mol Cancer Res (2009) 7(12):2022-30. doi:10.1158/1541-7786.MCR-09-0319

53. Scagnolari C, Zingariello P, Vecchiet J, Selvaggi C, Racciatti D, Taliani G, et al. Differential expression of interferon-induced microRNAs in patients with chronic hepatitis C virus infection treated with pegylated interferon alpha. Virol J (2010) 7:311. doi:10.1186/1743-422X-7-311

54. Wang P, Gu Y, Zhang Q, Han Y, Hou J, Lin L, et al. Identification of resting and type I IFN-activated human NK cell miRNomes reveals microRNA-378 and
microRNA-30e as negative regulators of NK cell cytotoxicity. J Immunol (2012) 189(1):211-21. doi:10.4049/jimmunol.1200609

55. Cheng M, Si Y, Niu Y, Liu X, Li X, Zhao J, et al. High-throughput profiling of alpha interferon- and interleukin-28B-regulated microRNAs and identification of let-7s with anti-hepatitis C virus activity by targeting IGF2BP1. J Virol (2013) 87(17):9707-18. doi:10.1128/JVI.00802-13

56. Bruni R, Marcantonio C, Tritarelli E, Tataseo P, Stellacci E, Costantino A, et al. An integrated approach identifies IFN-regulated microRNAs and targeted mRNAs modulated by different HCV replicon clones. BMC Genomics (2011) 12:485. doi:10.1186/1471-2164-12-485

57. Zhang J, Li S, Yan Q, Chen X, Yang Y, Liu X, et al. Interferon-beta induced microRNA-129-5p down-regulates HPV-18 E6 and E7 viral gene expression by targeting SP1 in cervical cancer cells. PLoS One (2013) 8(12):e81366. doi:10.1371/ journal.pone.0081366

58. Zhang J, Zhao H, Chen J, Xia B, Jin Y, Wei W, et al. Interferon- $\beta$-induced miR-155 inhibits osteoclast differentiation by targeting SOCS1 and MITF. FEBS Lett (2012) 586(19):3255-62. doi:10.1016/j.febslet.2012.06.047

59. Sekiya Y, Ogawa T, Iizuka M, Yoshizato K, Ikeda K, Kawada N. Down-regulation of cyclin E1 expression by microRNA- 195 accounts for interferon- $\beta$-induced inhibition of hepatic stellate cell proliferation. J Cell Physiol (2011) 226(10):2535-42. doi:10.1002/jcp. 22598

60. Fiorucci G, Chiantore MV, Mangino G, Romeo G. MicroRNAs in virus-induced tumorigenesis and IFN system. Cytokine Growth Factor Rev (2015) 26(2):183-94. doi:10.1016/j.cytogfr.2014.11.002

61. Hecker M, Thamilarasan M, Koczan D, Schroder I, Flechtner K, Freiesleben S, et al. MicroRNA expression changes during interferon-beta treatment in the peripheral blood of multiple sclerosis patients. Int J Mol Sci (2013) 14(8):16087-110. doi:10.3390/ijms140816087

62. Cilloniz C, Pantin-Jackwood MJ, Ni C, Carter VS, Korth MJ, Swayne DE, et al. Molecular signatures associated with Mxl-mediated resistance to highly pathogenic influenza virus infection: mechanisms of survival. J Virol (2012) 86(5):2437-46. doi:10.1128/JVI.06156-11

63. Dhodapkar KM, Banerjee D, Connolly J, Kukreja A, Matayeva E, Veri MC, et al. Selective blockade of the inhibitory Fcgamma receptor (FcgammaRIIB) in human dendritic cells and monocytes induces a type I interferon response program. J Exp Med (2007) 204(6):1359-69. doi:10.1084/jem.20062545

64. Turchinovich A, Burwinkel B. Distinct AGO1 and AGO2 associated miRNA profiles in human cells and blood plasma. RNA Biol (2012) 9(8):1066-75. doi: $10.4161 /$ rna.21083

65. Wiesen JL, Tomasi TB. Dicer is regulated by cellular stresses and interferons. Mol Immunol (2009) 46(6):1222-8. doi:10.1016/j.molimm.2008.11.012

66. Luciano DJ, Mirsky H, Vendetti NJ, Maas S. RNA editing of a miRNA precursor. RNA (2004) 10(8):1174-7. doi:10.1261/rna.7350304

67. Lecellier CH, Dunoyer P, Arar K, Lehmann-Che J, Eyquem S, Himber C, et al. A cellular microRNA mediates antiviral defense in human cells. Science (2005) 308(5721):557-60. doi:10.1126/science.1108784

68. Wang MB, Metzlaff M. RNA silencing and antiviral defense in plants. Curr Opin Plant Biol (2005) 8(2):216-22. doi:10.1016/j.pbi.2005.01.006

69. Chen Y, Shen A, Rider PJ, Yu Y, Wu K, Mu Y, et al. A liver-specific microRNA binds to a highly conserved RNA sequence of hepatitis B virus and negatively regulates viral gene expression and replication. FASEB J (2011) 25(12):4511-21. doi:10.1096/fj.11-187781

70. Jopling CL, Yi M, Lancaster AM, Lemon SM, Sarnow P. Modulation of hepatitis C virus RNA abundance by a liver-specific microRNA. Science (2005) 309(5740):1577-81. doi:10.1126/science.1113329

71. Nathans R, Chu CY, Serquina AK, Lu CC, Cao H, Rana TM. Cellular microRNA and P bodies modulate host-HIV-1 interactions. Mol Cell (2009) 34(6):696-709. doi:10.1016/j.molcel.2009.06.003

72. Perez JT, Pham AM, Lorini MH, Chua MA, Steel J, tenOever BR. MicroRNAmediated species-specific attenuation of influenza A virus. Nat Biotechnol (2009) 27(6):572-6. doi:10.1038/nbt.1542

73. Brennecke J, Stark A, Russell RB, Cohen SM. Principles of microRNA-target recognition. PLoS Biol (2005) 3(3):e85. doi:10.1371/journal.pbio.0030085

74. Bartel DP. MicroRNAs: target recognition and regulatory functions. Cell (2009) 136(2):215-33. doi:10.1016/j.cell.2009.01.002

75. Lewis BP, Burge CB, Bartel DP. Conserved seed pairing, often flanked by adenosines, indicates that thousands of human genes are microRNA targets. Cell (2005) 120(1):15-20. doi:10.1016/j.cell.2004.12.035 
76. Chi SW, Hannon GJ, Darnell RB. An alternative mode of microRNA target recognition. Nat Struct Mol Biol (2012) 19(3):321-7. doi:10.1038/nsmb.2230

77. Didiano D, Hobert O. Perfect seed pairing is not a generally reliable predictor for miRNA-target interactions. Nat Struct Mol Biol (2006) 13(9):849-51. doi:10.1038/ nsmb1138

78. Lal A, Navarro F, Maher CA, Maliszewski LE, Yan N, O’Day E, et al. miR-24 Inhibits cell proliferation by targeting E2F2, MYC, and other cell-cycle genes via binding to "seedless" 3'UTR microRNA recognition elements. Mol Cell (2009) 35(5):610-25. doi:10.1016/j.molcel.2009.08.020

79. Loeb GB, Khan AA, Canner D, HiattJB, Shendure J, Darnell RB, etal. Transcriptomewide miR-155 binding map reveals widespread noncanonical microRNA targeting. Mol Cell (2012) 48(5):760-70. doi:10.1016/j.molcel.2012.10.002

80. John B, Enright AJ, Aravin A, Tuschl T, Sander C, Marks DS. Human microRNA targets. PLoS Biol (2004) 2(11):e363. doi:10.1371/journal.pbio.0020363

81. Kiriakidou M, Nelson PT, Kouranov A, Fitziev P, Bouyioukos C, Mourelatos Z, et al. A combined computational-experimental approach predicts human microRNA targets. Genes Dev (2004) 18(10):1165-78. doi:10.1101/gad.1184704

82. Krek A, Grun D, Poy MN, Wolf R, Rosenberg L, Epstein EJ, et al. Combinatorial microRNA target predictions. Nat Genet (2005) 37(5):495-500. doi:10.1038/ ng1536

83. Miranda KC, Huynh T, Tay Y, Ang YS, Tam WL, Thomson AM, et al. A pattern-based method for the identification of microRNA binding sites and their corresponding heteroduplexes. Cell (2006) 126(6):1203-17. doi:10.1016/j. cell.2006.07.031
84. Kertesz M, Iovino N, Unnerstall U, Gaul U, Segal E. The role of site accessibility in microRNA target recognition. Nat Genet (2007) 39(10):1278-84. doi:10.1038/ng2135

85. Witkos TM, Koscianska E, Krzyzosiak WJ. Practical aspects of microRNA target prediction. Curr Mol Med (2011) 11(2):93-109. doi:10.2174/156652411794859250

86. Hafner M, Landthaler M, Burger L, Khorshid M, Hausser J, Berninger P, et al. Transcriptome-wide identification of RNA-binding protein and microRNA target sites by PAR-CLIP. Cell (2010) 141(1):129-41. doi:10.1016/j.cell.2010.03.009

87. Chi SW, Zang JB, Mele A, Darnell RB. Argonaute HITS-CLIP decodes microRNA-mRNA interaction maps. Nature (2009) 460(7254):479-86. doi:10.1038/ nature 08170

88. Helwak A, Kudla G, Dudnakova T, Tollervey D. Mapping the human miRNA interactome by CLASH reveals frequent noncanonical binding. Cell (2013) 153(3):654-65. doi:10.1016/j.cell.2013.03.043

Conflict of Interest Statement: The authors declare that the research was conducted in the absence of any commercial or financial relationships that could be construed as a potential conflict of interest.

Copyright (c) 2015 Forster, Tate and Hertzog. This is an open-access article distributed under the terms of the Creative Commons Attribution License (CC BY). The use, distribution or reproduction in other forums is permitted, provided the original author(s) or licensor are credited and that the original publication in this journal is cited, in accordance with accepted academic practice. No use, distribution or reproduction is permitted which does not comply with these terms. 